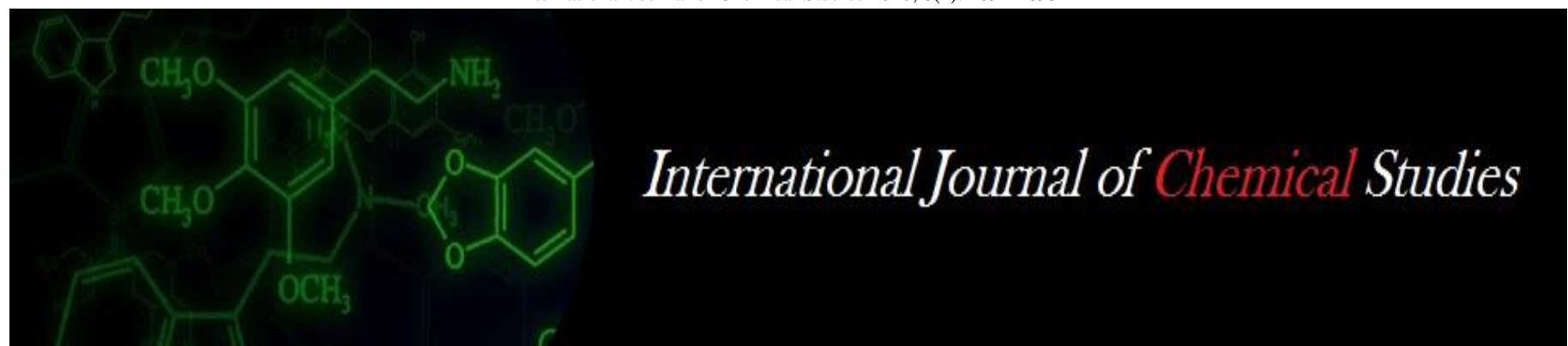

P-ISSN: 2349-8528

E-ISSN: 2321-4902

IJCS 2020; 8(1): 1891-1893

(C) 2020 IJCS

Received: 13-11-2019

Accepted: 15-12-2019

Nenavath Manikyam Ph.D. Scholar, Department of Farm Machinery and Power Engineering, Indira Gandhi Krishi Vishwavidyalaya, Raipur, Chhattisgarh, India

Prabhat Kumar Guru Scientist, Farm Machinery and Power, Crop Production Division, ICAR-National Rice Research Institute, Cuttack, Odisha, India

\section{RK Naik}

Associate Professor, Department of Farm Machinery and Power Engineering, Indira Gandhi Krishi Vishwavidyalaya, Raipur, Chhattisgarh, India

\section{Pushpraj Diwan}

Ph.D. Scholar, Department of

Farm Machinery and Power

Engineering, Indira Gandhi

Krishi Vishwavidyalaya, Raipur, Chhattisgarh, India
Corresponding Author: Nenavath Manikyam Ph.D. Scholar, Department of Farm Machinery and Power Engineering, Indira Gandhi Krishi Vishwavidyalaya, Raipur, Chhattisgarh, India

\section{Physical and engineering properties of urea briquettes relevant to design of ICAR-NRRI urea briquette applicator}

\author{
Nenavath Manikyam, Prabhat Kumar Guru, RK Naik and Pushpraj \\ Diwan
}

DOI: https://doi.org/10.22271/chemi.2020.v8.i1ab.8542

\begin{abstract}
Fertilizer deep placement technology is one of the effective measures to levitate fertilizer use efficiency. The physical and engineering properties of urea briquettes were studied for designing the urea briquette applicator. Metering mechanism is considered to be the heart of developed urea briquette applicator to place the urea briquettes at recommended dosage. The diameter of cup and cup depth were decided based on the maximum length and thickness of urea briquette. The mean length, breadth and thickness of urea briquettes were found to be $16.59 \mathrm{~mm}, 14.54 \mathrm{~mm}$ and $9.30 \mathrm{~mm}$, respectively. The mean size and sphericity of urea briquettes were found $13.10 \mathrm{~mm}$ and 0.79 , respectively. The angle of repose of urea briquettes was found as $33.6^{\circ}$. The average bulk density of urea briquette was found as $0.78 \mathrm{~g} \mathrm{cc}^{-1}$.
\end{abstract}

Keywords: Urea briquette, bulk density, size, shape and metring mechanism

\section{Introduction}

Production of paddy is input intensive, particularly, the modern high yielding varieties of paddy, consume large quantity of inorganic fertilizers and irrigation. Nitrogen $(\mathrm{N})$ plays a key role in rice production and is required in large amount. It is also the most limited nutrient in rice production and suffers from heavy system losses when applied as inorganic sources in the puddled field. In wetland paddy cultivation, only 30-40\% of nitrogen applied is successfully utilized (Datta et al., 1978) ${ }^{[3]}$. There is a need to improve nitrogen use efficiency of paddy crop to decrease the excessive application of chemical nitrogen and also minimize nitrogen emission to atmosphere. The most widely used nitrogen fertilizer is urea, which contains $46 \%$ $\mathrm{N}$, the highest of all solid fertilizers. Nitrogen fertilizer is usually broadcasted as prills in paddy fields prior to transplanting, followed by one or more top dressing in the flood water within the period from transplanting to flowering. The nitrogen fertilizer production is 13.41 MT and consumption is about 17.37 MT during 2015-16. (Anonymous, 2017)

Solid fertilizers can be applied by four different methods viz. broadcasting, placement, band placement and pallet application. Broadcasting is done in two ways spreading of fertilizers prior transplanting (basal application) and spreading of fertilizer prior to flowering (top dressing). Deep placement of nitrogenous fertilizer $(\mathrm{N})$ is one of the alternatives for increasing the nitrogen use efficiency of rice crop. Different forms (granular, urea briquettes, liquid) of nitrogenous fertilizer and their application technologies have been introduced for deep placement. Transplanting and deep placement of fertilizer were done simultaneously, coated fertilizer showed slow dissolving of $\mathrm{N}$ granules at 3-5 $\mathrm{cm}$ deep into soil and 4-5 cm away from seedlings. (Nayak et al., 2017) ${ }^{[7]}$.

\section{Materials and Methods}

The experiments of the measuring the physical and engineering properties of urea briquette were carried out in the laboratory of Agricultural Engineering, ICAR-National Rice Research Institute, Cuttack. 


\section{Making of urea briquettes}

The prilled urea was used for making briquettes. The prilled urea contains $\mathrm{N}-46 \%$ of fertilizer. Making of good quality briquette, the prilled urea should be free from foreign matter. The briquettes were made by compaction process. The prilled urea feed in the hopper of briquette making machine. The machine has two opposite rotating rollers with reduced spacing for making briquettes. The opposite rotating roller had pockets on its periphery. The urea briquettes were collected at discharge end. The good quality, broken, uneven briquettes were separated manually. The prepared urea briquettes were white in color and odourless.

\section{Size and shape of urea briquettes}

The shape and size were very important parameters to design the metering mechanism and placing briquette according to the recommended dosage in rice crop per hectare. The size of briquette was specified by length, width and thickness. The length, width and thickness were measured by digital vernier caliper, which having least count of $0.01 \mathrm{~mm}$. For measuring the dimensions twenty urea briquettes were randomly selected. The size of urea briquette was determined by following formula.

size $=\sqrt[3]{(\text { length } \times \text { breadth } \times \text { thickness })}$

\section{Sphericity and surface area of urea briquette}

The sphericity is a measure of shape character, compared to a sphere of the same volume. Sphericity affects the flow characteristics of briquettes in hopper and delivery tube also. The twenty urea briquettes were selected randomly from sample and measured. The degree of sphericity and surface area were calculated as follows (Mohsenin, 1986) ${ }^{[6]}$.

surface area $=\frac{13}{11}($ breadth + thickness $) \times$ length

spericity $=\frac{\text { size }}{\text { length }}$

\section{Weight of urea briquette}

Measuring of urea briquette weight was important to design and develop the size of hopper of applicator. To modify the weight of urea briquette some biodegradable materials can be used. This helps to attain the desirable application rate. The weight of individual urea briquette was measured using electronic weighing balance, having least count of $1 \mathrm{mg}$.

\section{Bulk density of urea briquette}

Bulk density of urea briquette was measured to determine the capacity of hopper. Bulk density of urea briquette was measured using a cylinder of known volume. The test sample was poured gently into cylinder. The point of pouring was moved around to keep the surface approximately level during filling. An excess was allowed to pile on the filled cylinder and then was removed by carefully passing a straight edge across the top of the cylinder. The cylinder with the test sample was then weighed, and the weight of the empty cylinder was subtracted to give the weight of the test sample. The procedure was repeated ten times and the average bulk density of the briquette was calculated. Bulk density was calculated as follows

$\mathrm{BD}=\frac{\mathrm{SW}}{\mathrm{V}}$
Where,

$\mathrm{BD}=$ Bulk density, $\mathrm{g} / \mathrm{cm}^{3}$,

$\mathrm{SW}=$ Weight of the test sample, $\mathrm{g}$, and

$\mathrm{V}=$ Volume of cylinder, $1000 \mathrm{~cm}^{3}$.

\section{Angle of repose of urea briquette}

Angle of repose of urea briquette was important parameter to be measured for design the slope of the applicator hopper. The angle of repose was determined by free fall method. The briquettes were dropped from certain height on floor. The dropped briquettes form a cone. The diameter and height of the cone was measured. The experiment was repeated ten times to determine mean angle of repose of urea briquette. The angle of repose was calculated using the following relationship:

$\theta=\tan ^{-1}\left(\frac{2 \mathrm{~h}}{\mathrm{~d}}\right)$

Where,

$\theta=$ Angle of repose, degree,

$\mathrm{h}=$ Height of the cone, $\mathrm{cm}$, and

$\mathrm{d}=$ Base diameter, $\mathrm{cm}$.

\section{Results and discussion}

Size, shape, sphericity and weight of urea briquette

Physical properties of urea briquettes relevant to design of urea briquette applicator viz. size, shape, surface area, sphericity, weight were determined. These properties were used for developing the urea briquette applicator. Depth and diameter of cup of metering mechanism would be influenced by the maximum length and thickness of urea briquette. The size, sphericity, surface and weight were determined as per methodology. The mean length, breadth and thickness of urea briquettes were found to be $16.59 \mathrm{~mm}, 14.54 \mathrm{~mm}$ and 9.30 $\mathrm{mm}$, respectively. The mean size and sphericity of urea briquette were found to be $13.10 \mathrm{~mm}$ and 0.788 , respectively. The mean weight of urea briquette and surface area of urea briquette were found to be $1.13 \mathrm{~g}$ and $470.44 \mathrm{~mm}^{2}$.

\section{Bulk density and angle of repose of urea briquette}

The bulk density and angle of repose of urea briquettes were determined as per methodology. Angle of repose affects the flow characteristics of urea briquettes in the hopper. The average bulk density of urea briquette was found to be $0.78 \mathrm{~g}$ $\mathrm{cc}^{-1}$. The angle of repose of urea briquettes was found to be $33.6^{\circ}$.

Table 1: Engineering properties of urea briquettes taken for design of metering unit

\begin{tabular}{|c|c|}
\hline Parameters & Value \\
\hline Length $(\mathrm{mm})$ & $16.59 \pm 1.284$ \\
\hline Breadth $(\mathrm{mm})$ & $14.54 \pm 0.575$ \\
\hline Thickness $(\mathrm{mm})$ & $9.30 \pm 0.249$ \\
\hline Size $(\mathrm{mm})$ & $13.10 \pm 0.521$ \\
\hline Surface area $\left(\mathrm{mm}^{2}\right)$ & $470.44 \pm 49.419$ \\
\hline Sphericity $(\%)$ & $0.788 \pm 0.042$ \\
\hline Weight $(\mathrm{g})$ & $1.13 \pm 0.105$ \\
\hline Bulk density $(\mathrm{g} / \mathrm{cc})$ & $0.78 \pm 0.009$ \\
\hline Angle of repose $\left(^{\circ}\right)$ & $33.65 \pm 0.429$ \\
\hline
\end{tabular}

\section{Conclusions}

Design values for urea briquette applicator metering unit All the engineering properties of urea briquettes were measured and average values were presented in Table 1. 
Based on the values, metering unit was designed. Diameter of cup was selected as $20 \mathrm{~mm}$ on the basis of maximum length $(16.59 \pm 1.284)$ of urea briquette and some allowance was also given for smooth picking and delivery. Depth of cup was selected on the basis of thickness $(9.3 \pm 0.249)$ of urea briquette, which was taken as nearly $50 \%$ of depth of cup. With different depth of cup was taken and tested for missing and multiple droppings. Depth of cup of $5.5 \mathrm{~mm}$ was found finalized which work satisfactorily and giving minimum missing and multiple droppings. If the depth of cup was more briquettes will sit deeper in the cup and if depth of cup was less the briquette fall early resulted in more missing percentage. Mean angle of repose was measured for mild steel surface and was found $33.65 \pm 0.429$. The angle of repose of cup, picking the urea briquette was selected based on the calculations.

Table 2: Design values for urea briquette applicator metering unit

\begin{tabular}{|c|c|}
\hline Parameters & Values \\
\hline Diameter of cup, mm & 20 \\
\hline Depth of cup, mm & 5.5 \\
\hline Distance between two cups, mm & 19.6 \\
\hline No. of cups per unit & 4 \\
\hline
\end{tabular}

\section{References}

1. Allaire SE, Parent LE. Physical properties of granular organic-based fertilisers, part 1: Static properties. Biosystems Engineering. 2004; 87(1):79-87.

2. Allaire SE, Parent LE. Physical properties of granular organic-based Fertilisers, Part 2: Dynamic properties related to water. Biosystems Engineering. 2004; 87(2):225-236.

3. De Datta SK, Magnaye CP, Moomaw JC. Efficiency of fertilizer nitrogen for flooded rice. Transactions of $9^{\text {th }}$ International Soil Science Congress. 1978; IV:67-76.

4. Deo MM, De D, Mani I, Iquebal MA. Physical and engineering properties of urea briquettes relevant to design of mechanical applicator. IJCS. 2019; 7(3):725728.

5. Indiastat. Year-wise Production and Consumption of Nitrogen fertilizer in India, 2017.

6. Mohsenin NN. Physical properties of plant and animial materials. Vol. 1. Structure, physical characterisitics and mechanical properties. Physical properties of plant and animial materials. Vol. 1. Structure, physical characterisitics and mechanical properties, 1970, 1.

7. Nayak AK, Mohanty Sangita, Chatterjee Dibyendu, Guru PK, Lal B, Shahid M et al. Placement of urea briquettes in lowland rice: An environment-friendly technology for enhancing yield and nitrogen use efficiency. NRRI Research Bulletin No.12 ICAR-National Rice Research Institute, Cuttack, Odisha 753006, India, 2017, 1-26.

8. Paré MC, Allaire SE, Khiari L, Nduwamungu C. Physical properties of organo - mineral fertilizers - Short Communication. Canadian Bio systems Engineering, 2009, 51 . 